\title{
Response to Applied Voltage to Polyurethane Soft Actuators with Loaded Weights
}

\author{
Masato Ohmukai' ${ }^{1}$ Jun Kyokane ${ }^{2}$ \\ ${ }^{1}$ Department of Electrical and Computer Engineering, Akashi College of Technology, Akashi, Japan \\ ${ }^{2}$ Center for International Education Toyohashi University of Technology, Toyohashi, Japan \\ Email: ohmukai@akashi.ac.jp
}

How to cite this paper: Ohmukai, M. and Kyokane, J. (2017) Response to Applied Voltage to Polyurethane Soft Actuators with Loaded Weights. World Journal of Engineering and Technology, 5, 383-388. https://doi.org/10.4236/wjet.2017.53032

Received: June 8, 2017

Accepted: July 9, 2017

Published: July 12, 2017

Copyright (C) 2017 by authors and Scientific Research Publishing Inc. This work is licensed under the Creative Commons Attribution International License (CC BY 4.0).

http://creativecommons.org/licenses/by/4.0/

\begin{abstract}
We are investigating a polymer soft actuator using a poly urethane elastomer film that bends by an applied voltage, which is based on the electrostriction. In this article, the bending magnitude was studied in a weight-loaded condition. It was found that the thinner film can bend the more without any load, but that the film of $200-\mu \mathrm{m}$ thickness gave the largest bending when weights were loaded. The thickness of some degree is critical for large bending torque.
\end{abstract}

\section{Keywords}

Poly Urethane Elastomer, Soft Actuator, Fullerenol, Dipole Moment

\section{Introduction}

We are investigating polyurethane elastomer for a polymer soft actuator. It has a quite simple form; a polymer film with a thickness of several hundred micrometers is sandwiched by vacuum-deposited metal layer on the both side. When direct current voltage as high as $1 \mathrm{kV}$ is applied across the film, it bends in several millimeters. Now it is the early stage of the development, the high voltage is needed to induce so little bending displacement. This kind of actuator, however, has the advantage of low-cost fabrication, soundless action, high energy efficiency and an environment-friendly aspect [1] [2].

The application to the soft actuator has not been so developed until now. In the future, this kind of soft actuator can be applied to smoothly moving robotic fingers for example. One of the big problems that deter the application is the unpractical high voltage to drive the device though some applications to robotic hand have been reported [3]. We expect further development to reduce the voltage required for the operation. There are even some other ideas of its application such as artificial muscles [4]. The realistic application is now thought to be a 
gas valve for making use of bending motion of the film attached over a hole on the wall of a pipe. In this case it seems to require only little force if arrangement of the piping system is well designed.

We are now interested in the magnitude of the induced force in the soft actuator. The magnitude of the bending force is particularly critical for grasping stuffs after all and a practically important parameter at the same time. In this article, we show the bending features of the actuator loaded with weights as well as the difference in the bending characteristics in a different thickness of the film.

\section{Experimental}

A film of polyurethane elastomer was provided by a casting in a mold into which prepolymer and extender were put together for curing. The addition of fullerenol in this process was quite effective to enhance the bending displacement [5]. In the literature we reported that the displacement was the largest when the concentration of fullerenol was $0.25 \%$ and so we always added $0.25 \%$ of fullerenol through the experiments in this article. The process to fabricate the actuator was fully reported in the literature [5]; we briefly describe it here.

We synthesized fullerenol in our laboratory by hydrolyzing multivalent sulfonated fullerene. The multivalent sulfonated fullerene was obtained by mixing of fullerene $(3 \mathrm{~g})$ and oleum $(45 \mathrm{ml})$ for 7 days. The hydrolysis was performed by mixing the sulfonated fullerene $(3 \mathrm{~g})$ and distilled water $(60 \mathrm{ml})$ for 4 days. The time and temperature at mixing of fullerene and oleum may determine the degree of sulfonation.

We next describe the preparation of prepolymer. Prepolymer was synthesized using P-3010 (Kuraray Co. Ltd.) as polyol and para-phenylene diisocyanate for the replacement of the hydroxyl groups to isocyanate groups. The mass ratio of the two materials was determined in such a way that all para-phenylene diisocyanate were replaced by all $\mathrm{OH}$ groups on the polyol. It was necessary to heat up to around $100^{\circ} \mathrm{C}$ in vacuum chamber to eliminate water thoroughly that may exist in the material or even in the air.

The final stage is blending the prepolymer with some kinds of extender including fullerenol and curing in a mold. We used 1,2-propanediol (1,2-PD) and trimethylolpropane (TMP) as an extender. We mixed fullerenol into it at this stage. We should pay attention to degassing enough before and after mixing these materials because of their high viscosity. Degassing was performed so that we kept it at about $80^{\circ} \mathrm{C}$ in vacuum. The mixture was put into a mold of stainless steel and cured for 18 hours.

The thickness of the film was controlled by selecting a spacer put between a pair of two molds. We obtained three kinds of thicknesses: 100, 200 and $400 \mu \mathrm{m}$. The film was taken out from the mold after curing, cut into a rectangular form of 15 by $50 \mathrm{~mm}$, and then Au electrodes as thick as a few micrometers were deposited onto both front and back faces by a vacuum evaporation method.

As for the measurement of the bending displacement, we hang the actuator by holding it at the upside with a clip (Figure 1). The bending displacement at the 
other end downward of the actuator was measured by focusing a laser light with a laser displacement meter (LB-1000 by Keyence Corp). The weight of 200 or $500 \mathrm{mg}$ was hanged at the bottom of the film.

\section{Results}

We show the results without a weight for the three samples with a different thickness in Figure 2. We successfully obtained the achievement of several ten millimeters to bend at less than $1 \mathrm{kV}$. We should pay attention to the axis of abscissas that is applied voltage, not electric field. When the thickness is small, the induced electric field in the film is large, more precisely it is inversely proportional to the thickness. The sample with $100 \mu \mathrm{m}$ is deflected most in Figure 2, which is natural from the point of view.

We next see the results shown in Figure 3 that is when the weight of $200 \mathrm{mg}$

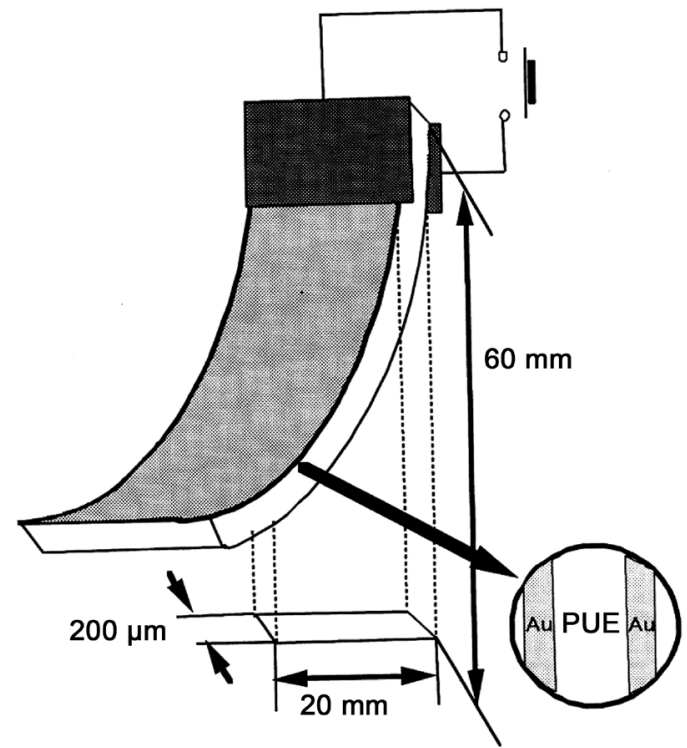

Figure 1. Dimension of polyurethane elastomer and its external appearance of bending action.

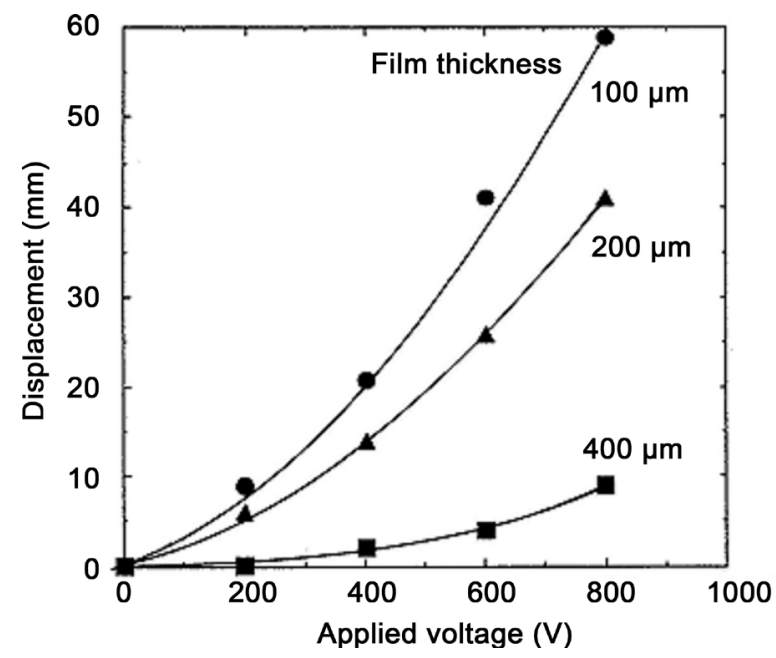

Figure 2. The bending displacement of the film as a function of applied voltage. 


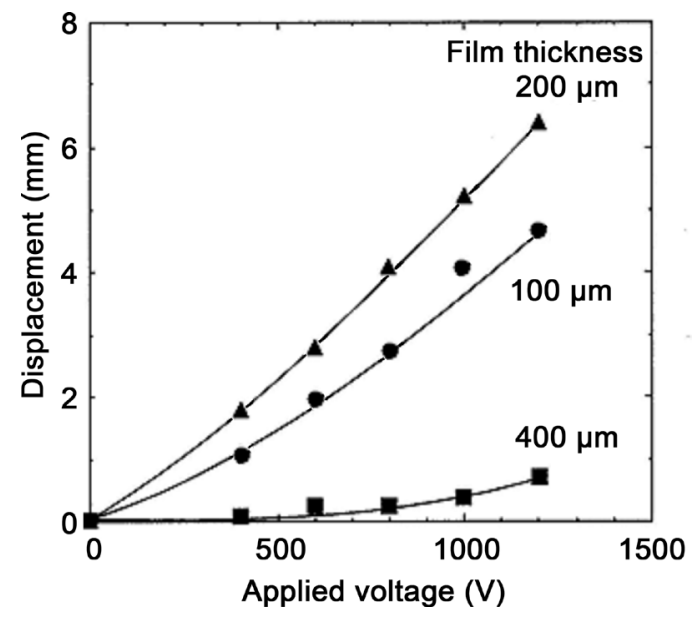

Figure 3. The bending displacement of the film as a function of applied voltage when the weight of $200 \mathrm{mg}$ was loaded.

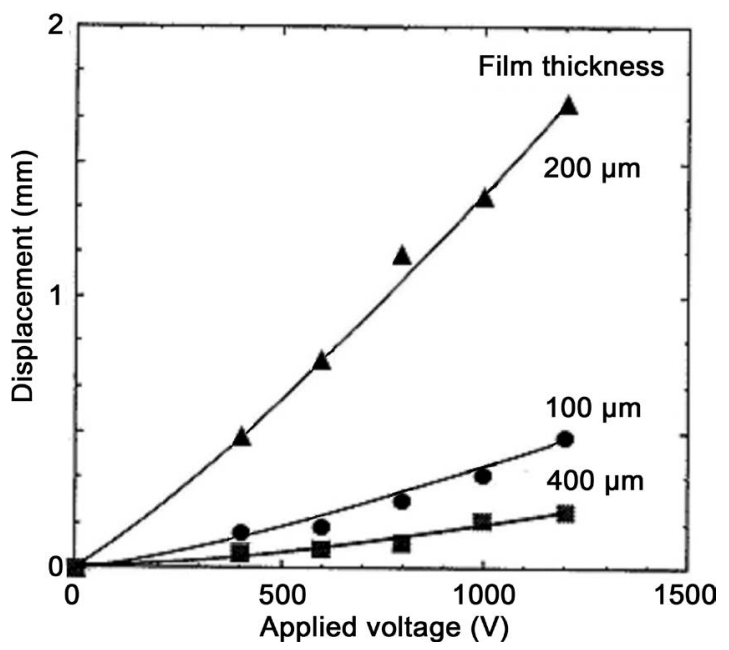

Figure 4. The bending displacement of the film as a function of applied voltage when the weight of $500 \mathrm{mg}$ was loaded.

was applied. The displacement totally declines to several millimeters. This decline is more noticeable when the weight increases up to $500 \mathrm{mg}$ as is shown in Figure 4. A remarkable feature is that in Figure 3 and Figure 4 the sample with $200 \mu \mathrm{m}$ bended more than that with $100 \mu \mathrm{m}$. These results were quite reproducible.

\section{Discussion}

The change in bending characteristic based on the different thickness has been reported in the literature [6]. It was concluded that at the same electric field the thicker film can bend greater and nearly proportional to the electric field at the same time. A sample with $100 \mu \mathrm{m}$ shows bowing downward in the bending displacement vs. electric field relationship; in other words, there apparently exists a kind of threshold to bend.

Figure 2 obviously shows that the $100-\mu \mathrm{m}$ sample gives the largest displacement in the three samples at the same applied voltage, which was mentioned 
above. From Figures 2-4, the absolute value in the axis of ordinates becomes smaller and smaller as the weight gets heavier. We notice the interesting point that the displacement of the $200-\mu \mathrm{m}$ sample is the largest, not the $100-\mu \mathrm{m}$ sample, in Figure 3 and Figure 4. When the weight is $500 \mathrm{mg}$ (Figure 4), the 100and $400-\mu \mathrm{m}$ samples shows the similar degree of displacement. From these facts we can say that the $100-\mu \mathrm{m}$ sample deforms to a great extent without weight but not so much when a weight is loaded. It means the force to bend in the sample is quite small even though the electric field is applied largely. It is possibly because the thinner film is not stiff enough physically to move against the weight although it can cause a relatively high electric field with the same applied voltage.

We can draw a part of conclusion below from the discussion above. As the film is thin, it is advantageous because the electric field becomes large at the same applied voltage. However, the mechanical strength becomes weak on the other hand. Since the actuator holds these two conflicting properties, there exists an optimal thickness for a given weight or force. As far as our experimental results are concerned, a $200-\mu \mathrm{m}$ sample is optimal thickness, for the weight between 200 and $500 \mathrm{mg}$. We should pay attention to the fact that in our experiments the force by the weight was loaded in the direction parallel to the film surface. If the force is applied in the direction normal to the film surface, a different result may be obtained. The existence of an optimal thickness is, we believe, maintained in this case too. The idea may be explained recent understanding of the combination of hard- and soft-segment composition [7] [8].

\section{Conclusion}

We fabricated three kinds of soft actuator with a different thickness, which are made of polyurethane elastomer doped with fullerenol. We then investigated the dependence of the displacement of bending on applied voltage. We performed an investigation on the relationship between the applied voltages and bending displacements with a force by a weight was loaded in the direction parallel to the film surface from the practical point of view. In our experiment, the thinnest film $(100 \mu \mathrm{m})$ bended most without any weight while the film having a moderate thickness $(200 \mu \mathrm{m})$ showed the most bending displacement with a weight (200 or $500 \mathrm{mg}$ ). The results told us that there is an optimal thickness such that the film thickness has a tradeoff between the induced electric field in the film and the mechanical strength.

\section{References}

[1] Shankar, R., Ghosh, T.K. and Spontak, R.J. (2007) Dielectric Elastomers as NextGeneration Polymeric Actuators. Soft Matter, 3, 1116-1129. https://doi.org/10.1039/b705737g

[2] Pelrine, R.E., Kornbluh, R.D. and Joseph, J.P. (1998) Electrostriction of Polymer Dielectrics with Compliant Electrodes as a Means of Actuation. Sensors and Actuators $A$, 64, 77-85. https://doi.org/10.1016/S0924-4247(97)01657-9

[3] Ueda, T., Kasazaki, T., Kunitake, N., Hirai, T., Kyokane, J. and Yoshino, K. (1997) Polyurethane Elastomer Actuator. Synthetic Metals, 85, 1415-1416. 
https://doi.org/10.1016/S0379-6779(97)80299-8

[4] Nam, J.-D., Choi, H.R., Koo, J.C., Lee, Y.K. and Kim, K.J. (2007) Dielectric Elastomers for Artificial Muscles. In: Kim, K.J. and Tadokoro, S., Eds., Electroactive Polymers for Robotic Applications. Artificial Muscles and Sensors, Springer Publishing Co., New York, 37-48. https://doi.org/10.1007/978-1-84628-372-7_2

[5] Ohmukai, M. and Kyoknane, J. (2014) Optimum Fullerenol Concentration for Actuation of Polyurethane Elastomer Film. Materials Focus, 3, 78-80.

https://doi.org/10.1166/mat.2014.1141

[6] Ohmukai, M. and Kyokane, J. (2014) Bending Characteristic of Polyurethane Soft Actuator: Dependence on Film Thickness. Advanced Science, Engineering and Medicine, 6, 715-717. https://doi.org/10.1166/asem.2014.1560

[7] Nozaki, S., Hirai, T., Higaki, Y., Yoshinaga, K., Kojio, K. and Takahara, A. (2017) Effect of Chain Architecture of Polyol with Secondary Hydroxyl Group on Aggregation Structure and Mechanical Properties of Polyurethane Elastomer. Polymer, 116, 423-428. https://doi.org/10.1016/j.polymer.2017.03.031

[8] Kumagai, S., Motokucho, S., Yabuki, R., Anzai, A., Kameda, T., Watanabe, A., Nakatani, H. and Yoshioka, T. (2017) Effects of Hard- and Soft-Segment Composition on Pyrolysis Characteristics of MDI, BD, and PTMG-Based Polyurethane Elastomers. Journal of Analytical and Applied Pyrolysis, in press.

https://doi.org/10.1016/j.jaap.2017.05.012

\section{Submit or recommend next manuscript to SCIRP and we will provide best service for you:}

Accepting pre-submission inquiries through Email, Facebook, LinkedIn, Twitter, etc. A wide selection of journals (inclusive of 9 subjects, more than 200 journals) Providing 24-hour high-quality service User-friendly online submission system Fair and swift peer-review system Efficient typesetting and proofreading procedure Display of the result of downloads and visits, as well as the number of cited articles Maximum dissemination of your research work

Submit your manuscript at: http://papersubmission.scirp.org/

Or contactwjet@scirp.org 